\title{
SPONTANEOUS CERVICAL ARTERY DISSECTION
}

\section{An update on clinical and diagnostic aspects}

\author{
Cynthia Resende Campos-Herrera', Milberto Scaff ${ }^{2}$, Fábio luji Yamamoto ${ }^{2}$, Adriana Bastos Conforto ${ }^{2}$
}

\begin{abstract}
Spontaneous cervical arterial dissection (SCAD) is a non-traumatic tear or disruption in the wall of the internal carotid arteries or the vertebral arteries. It accounts for about $25 \%$ of strokes in patients aged under 45 years. Awareness of its clinical features and advances in imaging over the last two decades have contributed to earlier identification of this condition. SCAD has become the commonest form of vascular lesion identified in the cervical carotid and vertebral arteries, second only to atherosclerosis. This review is an update on the epidemiology, vulnerable arterial segments, risk factors, clinical features, diagnosis, current treatment and prognosis of SCAD.
\end{abstract}

KEY WORDS: dissection, carotid, vertebral artery, stroke, angiography.

\begin{abstract}
Dissecção espontânea da artéria cervical: atualização sobre aspectos clínicos e diagnósticos
Resumo - Dissecção arterial cervical espontânea (DACE) é uma laceração ou ruptura na parede de artérias cervicais responsáveis pela irrigação sanguínea cerebral: artérias carótidas internas e artérias vertebrais. É responsável por cerca de $25 \%$ dos acidentes vasculares cerebrais isquêmicos em pacientes abaixo de 45 anos de idade. Ao longo das duas últimas décadas, com a maior conscientização sobre suas manifestações clínicas e o avanço das técnicas de neuroimagem, a DACE tem sido diagnosticada mais precocemente, tornando-se o tipo de lesão vascular mais comumente identificado nas artérias cervicais, sendo superada apenas pelas lesões ateroscleróticas. Esta revisão é uma atualização sobre a epidemiologia, segmentos arteriais mais vulneráveis, fatores de risco, manifestações clínicas, diagnóstico, tratamento e prognóstico da DACE.
\end{abstract}

PALAVRAS-CHAVE: dissecção, artéria vertebral, acidente vascular cerebral, arteriografia.

Spontaneous cervical arterial dissection (SCAD) is a non-traumatic tear or disruption in the wall of the brainsupplying arteries: the internal carotid artery (ICA) and the vertebral artery (VA) ${ }^{1,2}$. The dissection leads to accumulation of blood within the layers of the artery, between the intima and the media (subintimal dissection) or between the media and the adventitia (subadventitial dissection), resulting in an intramural hematoma that can spread along the vessel proximally and distally ${ }^{2}$. The intramural hematoma can cause stenosis or occlusion of the vessel lumen. The anatomic disruption of the endothelium in subintimal dissections or impaired blood flow due to the narrowing of the lumen predispose to local thrombus formation which can either occlude the vessel or embolize distally resulting in brain infarction or eye ischemia ${ }^{3,4}$. Subadventitial dissections lead to formation of aneurysms and, if the dissection spreads intracranially, to subarachnoid hemorrhage $e^{1,2}$. Neurological focal deficits can occur either because of artery-to-artery embolization of the intraluminal thrombus, or by an hemodynamic mechanism, with subsequent reduced perfusion in the brain territory supplied by the stenosed artery ${ }^{2,5,6}$.

The first clear case of SCAD - a patient with a spontaneous dissecting aneurysm of the internal carotid artery (ICA) - was described in 1959,7. But it was the work of Fisher et al. in the late 1970s that led to the recognition of the clinical and radiological features of dissection syndromes facilitating their antemortem diagnosis ${ }^{9}$. Over the last two decades, as awareness of its clinical features increased, and with advances in imaging, SCAD has been identified increasingly earlier, becoming the commonest form of vascular lesion identified in the cervical carotid and vertebral arteries, second only to atherosclerosis'.

This review is an update on the epidemiology, vulner-

${ }^{1}$ Neurologist; Municipal Hospital Mário Gatti, Campinas, SP, Former Post-Graduation student (PhD) of the Department of Neurology of the Faculty of Medicine of the University of São Paulo, São Paulo SP, Brazil (USP); ${ }^{2}$ Neurologists, Division of Neurology, Hospital of Clinics, USP.

Received 3 September 2008. Accepted 5 October 2008.

Dra. Adriana Bastos Conforto - Avenida Dr. Enéas de Carvalho Aguiar 255/5084 - 05403-000 São Paulo SP - Brasil. E-mail addresses: abconf@usp.br; abconf@yahoo.com. 
able arterial segments, risk factors, clinical features, diagnosis, current treatment and prognosis of SCAD.

\section{EPIDEMIOLOGY}

SCAD accounts for about $25 \%$ of strokes in patients under 45 years old ${ }^{10,11}$. The annual incidence is estimated to be 2.6 to 5 per $100000^{12,13}$. The incidence of ICA dissection is approximately two times higher than the incidence of VA dissection". Simultaneous multivessel dissections may occur in up to $30 \%$ of the cases ${ }^{14,15}$.

SCAD may affect all age groups, but there is a distinct peak in the fifth decade of life $e^{12,14}$. There is no clear gender predominance, but it occurs approximately five years earlier in women than it does in men ${ }^{13}$. In Brazil, two case-series studies on SCAD were published based on the clinical experience of three tertiary health care centers and showed demographic findings similar to the international series ${ }^{16,17}$.

\section{VULNERABLE ARTERIAL SEGMENTS}

The most common locations of SCAD are regions where the arteries are more mobile and not firmly anchored to other arteries or bony structures ${ }^{1,2,18}$.

The ICA is relatively fixed proximally, at the origin from the common carotid artery, and distally, at the point of penetration in the petrous portion of the temporal bone. The arterial segment between these two points of anchorage is mobile and therefore vulnerable to stretching, especially during neck hyperextension with head rotation, which can stretch the ICA against an upper cervical vertebra or a proeminent styloid process ${ }^{1,2}$. The tear often occurs around $3 \mathrm{~cm}$ above the carotid bifurcation ${ }^{2,18}$.

The extracranial VA is anchored at its origin from the subclavian artery (V1 segment), during its course through the spine within the intervertebral foramina (V2 segment), and by the dura at the point of intracranial penetration. The V1 segment is vulnerable to dissection, usually beginning above the origin from the subclavian artery. It is relatively fixed at the bony orifice of the $\mathrm{C} 6$ intervertebral foramen but the increased mobility at C5-C6 level makes it vulnerable to stretching ${ }^{18}$. The short segments between the intervertebral foramina in the V2 segment are also common sites of dissection, as they are vulnerable to longitudinal stretching ${ }^{2,18,19}$. The rotation in the atlantoaxial joint and the flexion and extension in the atlanto-occipital joint increases risk of stretching at V3 segment ${ }^{18,19}$. Extracranial VA dissection extends intracranially in about $10 \%$ of cases because, unlike ICA which enters the skull through a narrow foramen that can hold spreading of the dissection, the VA enters the skull through the foramen magnum².

\section{RISK FACTORS}

Patients with SCAD may report trivial precipitating events or preceding minor neck traumas such as sudden or prolonged neck extension, coughing, vomiting or sneezing ${ }^{1,2,20}$. Iatrogenic causes such as endotracheal intubation, positioning of neck during anesthesia, tonsil surgery, tooth extraction on a dental chair, among others, have also been described ${ }^{2,20}$. Chiropractics have been repeatedly discussed as a risk factor for cervical artery dissections, especially for VA dissections ${ }^{20-22}$. However, a cause-effect relationship between these procedures and dissections is still debatable.

Other risk factors have been increasingly taken into consideration in the pathogenesis of SCAD: mild hyperhomocysteinemia ${ }^{23}$; TT genotype of the T677C polymorphism in the methylenetetrahydrofolate reductase gene ${ }^{24}$; migraine ${ }^{25,26}$; recent respiratory tract infection ${ }^{27}$. Their pathogenic mechanisms are also still unclear ${ }^{1,4,27}$.

Hereditary connective tissue disorders like vascular Ehlers-Danlos syndrome (EDS), fibromuscular dysplasia and Marfan syndrome usually present abnormalities on the arterial wall and are known to be risk factors for dissection ${ }^{28}$. As the mechanical stability and elasticity of the vessel wall is provided by connective tissue elements, structural deviations in the main components, collagen and elastic fibers, may lead to functional impairment, predisposing to dissection of the arterial wall at given points of minor resistance ${ }^{15}$. Some otherwise healthy individuals with SCAD can present subclinical ultrastructural abnormalities of dermal connective tissue ${ }^{15,29}$. In this setting, the underlying arteriopathy may be the vascular phenotype of a subclinical connective tissue disorder ${ }^{15,24}$.

\section{CLINICAL FEATURES}

The clinical features of SCAD depend on the anatomy of the affected vessel and its arterial supply. Local symptoms and signs, as well as ischemic events can occur either combined or in isolation.

\section{Local symptoms and signs}

Local symptoms and signs due to the arterial lesion itself can occur as the sole clinical manifestation or can be warning symptoms that precede a transient ischemic attack (TIA) or stroke by hours or days ${ }^{2,31}$. This time is often shorter in ICA dissection than in VA dissection ${ }^{1,2}$. Intense headache and cervical pain, usually unilateral, may occur in up to $75 \%$ of patients with SCAD, as the cervical arteries are heavily innervated by pain fibers ${ }^{31}$. The real prevalence of SCAD causing exclusively local symptoms is unknown because not all patients with such symptoms undergo diagnostic investigation ${ }^{2}$. Besides, as the warning symptoms can be missed or underdiagnosed, the absolute risk of ischemic complications beyond the onset of local manifestations is also unknown ${ }^{30}$.

In ICA dissection, headache is often frontotemporal, 
but it may affect the entire hemicranium, or even the parieto-occipital area ${ }^{32}$. It is usually gradual, pulsating and steady, and most of the patients consider it to be different from previously perceived headaches ${ }^{32}$. However, in some patients with a history of migraine, the dissectionrelated headache may resemble their usual migraine at$\operatorname{tack}^{31-33}$. Neck pain is usually located in the upper anterolateral cervical region and can extend into the ipsilateral jaw and face ${ }^{31,32,34}$.

Although Horner syndrome consisting essentially of ptosis, miosis and supraorbital anhidrosis, is a well-known typical manifestation of ICA dissection, it occurs in less than $40 \%$ of the cases ${ }^{35}$. Still, an acute Horner syndrome, even in isolation, should be considered as a medical emergency and promptly investigated, as there is a $12 \%$ stroke risk within 30 days after its onset ${ }^{34}$. Other local symptoms in ICA dissection include pulsatile tinnitus and lower cranial nerves (IX-XII) impairment ${ }^{35}$. Pulsatile tinnitus is explained by the course of the ICA near the tympanic membrane ${ }^{2,35}$. Lower cranial nerves may be compressed or stretched near to the jugular and hypoglossal foramen, especially in subadventitial dissections ${ }^{1,2}$.

In VA dissection, the classical clinical presentation is occipital headache, posterior neck pain, or both, usually on the same side of the dissection, associated with posterior circulation ischemia ${ }^{2,37,38}$. The pain is usually sudden, sharp, severe, steady and different from previous pain episodes ${ }^{32,37}$. The predominantly occipital location of headache is explained by the innervations of this region by the upper cervical nerves ${ }^{2,37}$. Neck pain may be unilateral, even in bilateral VA dissection, and may radiate to the $\operatorname{arm}^{1,32,38}$. It might be difficult to distinguish dissected-related neck pain from musculoskeletal neck pain ${ }^{37}$.

\section{Ischemic events}

In ICA dissection, embolism of the carotid clot usually causes middle cerebral artery territory ischemic stroke and, less frequently, retinal infarct ${ }^{35}$. Brief and recurrent monocular visual loss episodes and ischemic optic neuropathy are assumed to be mainly due to hypoperfusion than due to embolism ${ }^{39}$. Patients with ICA dissection and ischemic events present significant higher prevalences of stenoses and occlusions and significant lower prevalences of Horner syndrome and lower cranial nerves palsy (symptoms more frequent in subadventitial dissection) than patients with no ischemic events ${ }^{34}$. This suggests that subadventitial dissection is less likely to cause stroke.

In VA dissection, ischemia usually involves structures within the proximal posterior circulation, such as the lateral medulla and cerebellum, but distal territories such as the basilar artery and posterior cerebral arteries can also be affected ${ }^{37}$. The main symptoms are vertigo, nausea, vomiting, diplopia, visual blurring, dysphasia, hoarse- ness and gait disturbance ${ }^{37,40}$. Complete or partial Wallenberg syndrome is commonly observed ${ }^{37,40}$. Rarely, VA dissection can cause cervical spinal cord ischemia because both intracranial VA supply branches to the rostral cervical spinal cord segments ${ }^{40}$. Cervical root impairment due to aneurismal dilatation of the dissected artery near to the nerve roots (mostly at the C5-C6 level) is rare ${ }^{40}$. If the dissection extends intracranially, subarachnoid hemorrhage may occur because the adventitia layer becomes thinner intracranially ${ }^{1,2}$. TIA is less common in VA dissection than in ICA dissection ${ }^{2}$.

\section{DIAGNOSIS}

For patients with few or no risk factors for atherosclerotic disease who present with stroke or TIA, the diagnosis of SCAD should be always considered ${ }^{2,4}$. Although nonspecific, history of minor trauma preceding a new-onset headache or neck pain might provides clues for clinical suspicion, especially in young and middle-aged patients.

Digital subtraction angiography (DSA) is still the gold standard for SCAD diagnosis. However, over the last decade, less invasive methods such as magnetic resonance imaging (MRI), magnetic resonance angiography (MRA) and computed tomography angiography (CTA) have been shown to be sensitive and specific for diagnosis as well as for subsequent monitoring of lesion evolvement ${ }^{41}$.

As a first approach, imaging with MRA and MRI with fat-saturated cross-sectional images in the regions of vascular abnormalities is recommended ${ }^{1,41}$. They allow direct demonstration of an intramural hematoma and enable precise determination of the dissection extent. MRA can show vascular narrowing, occlusion or dilatations that are suggestive of dissection (along with the clinical features) ${ }^{41}$. However, in VA dissection, MRA might be of limited usefulness, especially when the dissection occurs more distally, because this artery loops in and out of the plane of imaging in this segment ${ }^{41}$. MRI with fat saturation can detect the intramural hematoma, which shows a typical evolution of signal intensity over the time ${ }^{41}$. The shape of the hematoma (crescentic, oval or circumferential) varies according to the relation between the axis of the affected vessel and the imaging plane. If the magnetic resonance studies are not diagnostic, CTA or DSA are nearly always enough to confirm the diagnosis'.

DSA is the best method to evidence filiform stenosis with slow flow, fibromuscular dysplasia and other irregularities of the arterial lumen ${ }^{2,18,42}$. The most common angiographic appearance is a relatively smooth or slightly irregular tapered narrowing called string sign ${ }^{41,42}$. Occlusive dissection is less specific, but it may show a flame-like shape, especially in ICA dissection ${ }^{42}$. Intimal flap, false lumen or aneurysm (with or without stenosis or irregularities) are pathognomonic findings, but less commonly ob- 

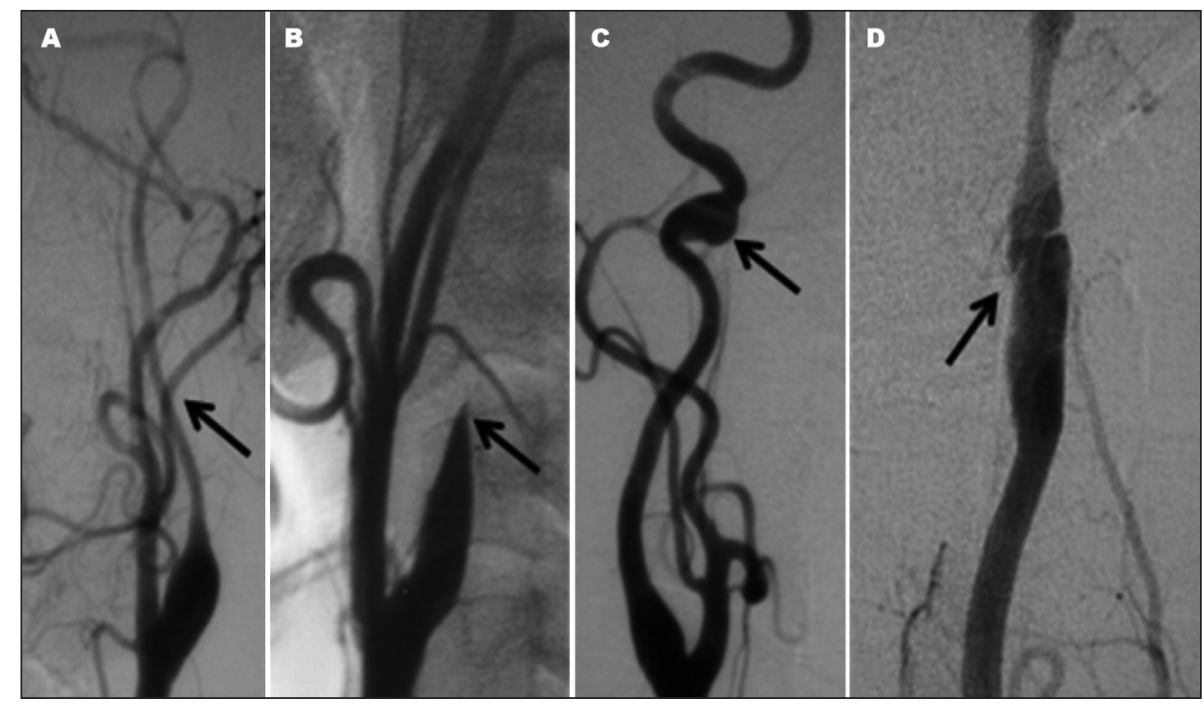

Fig 1. Some angiographic findings (arrows) in ICA (A, B, C) and VA (D) dissection. (A) String sign; (B) Flame-like shape occlusive dissection; (C) Aneurysm; (D) Intimal flap.

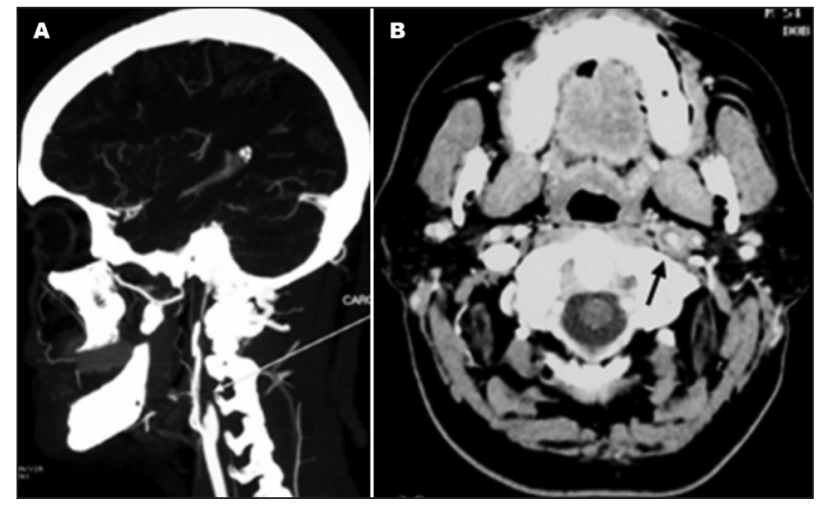

Fig 2. CTA findings in a patient with left ICA dissection. (A) Flamelike shape occlusion (white arrow); (B) mural thickening with eccentric arterial lumen (black arrow).

served $^{42}$ (Fig 1). Atherosclerotic vessel lesions are uncommon in SCAD patients. ${ }^{4}$.

CTA has been performed, particularly in patients presenting with contraindications for MRI. Multidetector scans have improved the quality of imaging, but the diagnostic potential in patients with cervical artery dissections has not been examined systematically. Although less invasive than DSA, this method involves exposure to $X-$ rays $^{43}$. SCAD on CTA may present with occlusion, stenosis, pseudoaneurysm, target picture, mural thickening, or an eccentric arterial lumen, which seems to be the most reliable indicator of acute dissection ${ }^{43}$ (Fig 2).

Conventional ultrasound has been currently underused for SCAD diagnosis. When performed by an experienced examiner, nonspecific abnormal hemodynamic findings (stenosis or occlusion) can be detected, raising the suspicion of SCAD, especially if no or mild atherosclerosis is observed ${ }^{44}$. The use of B-mode and color Doppler imaging may be helpful, as they can sometimes show taper- ing stenoses, double lumen, dissecting membranes, vessel wall irregularities and aneurysms ${ }^{1,44}$. However, further imaging methods are usually performed in order to confirm the diagnosis of dissection. In practice, ultrasound seems to be more useful for non-invasive monitoring of vessel recanalization and guidance of antithrombotic therapy?.

\section{TREATMENT}

Considering that most of SCAD-related strokes seem to result from a thromboembolic mechanism ${ }^{3}$, conservative management with antithrombotic therapy to prevent further ischemic events sounds a prudent strategy. However, the efficacy of this therapy has never been established, as well as its benefit in the prevention of long-term ischemic events after SCAD ${ }^{30,45}$.

Heparin is usually prescribed in the acute phase, followed by oral anticoagulants for a mean period of three months ${ }^{1,2}$. After then, anticoagulants are frequently switched to antiplatelets ${ }^{1,2}$. Some advise continuation of antiplatelet drugs when arterial abnormalities remain, such as stenoses or aneurysms, but there is no clear evidence of benefit regarding this therapeutical strategy $y^{30,45}$. Actually, the very low risk of long-term ischemic events, even in patients with persistent arterial lesions, makes it difficult to evaluate the long-term benefit of antithrombotic drugs in SCAD. It is important to consider that, besides the risk of intracranial or systemic bleeding, anticoagulants may carry a theoretical risk of increase of the intramural hematoma, although this has not been confirmed by everyday practice ${ }^{30,45,46}$.

Whether anticoagulants are better than antiplatelet drugs in the prevention of early or late recurrent events remains unknown. One prospective observational study found that the rate of recurrent TIA and ischemic stroke or death was higher in patients treated with aspirin (12.4\%) 
than with anticoagulation (8.3\%), but the results were not statistically significant ${ }^{45}$.

Safety and efficacy of intravenous or intra-arterial thrombolysis in patients with acute stroke due to SCAD have not been assessed in any controlled randomized trial. Despite the theoretical risks of extension of the intramural hematoma, worsening of the luminal narrowing, clot dislocation and vessel rupture, none of the major intravenous thrombolysis trials excluded patients with $\mathrm{SCAD}^{47}$; these patients were neither specifically identified prior to treatment, nor were part of subgroup analysis. In spite of providing insufficient data for assessment of efficacy, four non-randomised studies of intravenous thrombolysis showed that complication rates were no greater than thrombolysis for other ischemic stroke etiologies, suggesting that this treatment should not be withheld in patients with suspected SCAD ${ }^{48-51}$. Regarding intra-arterial thrombolysis (IAT), few case reports have been published and showed no rupture of the dissected vessel, intracranial or subarachnoid hemorrhage or peri-interventional arterial embolism ${ }^{52,53}$.

Surgery or endovascular procedures have been described in patients with persistent or progressive symptoms despite adequate clinical therapy, in those with hemodynamically significant residual stenosis, or in the presence of contraindications to anticoagulant therapy ${ }^{31,54}$. The rational for such procedures is the speculation of a possible higher risk of stroke in these patients, especially in those with persistent stenosis ${ }^{55}$. Nevertheless, prospective studies showed that the stroke risk in patients with persistent severe stenosis or occlusion as well as in patients with persistent aneurysm is very low ${ }^{55-57}$. Therefore, there is no evidence to support the routine use of invasive therapies in the vast majority of patients with persistent arterial lesions after SCAD.

\section{PROGNOSIS}

Prognosis of SCAD involves neurological and arterial outcomes. Neurological or functional outcome is related to the severity of the ischemic insult. The overall functional prognosis of patients with stroke due to SCAD does not seem to differ from that of young patients with stroke due to other causes ${ }^{58,59}$. The rate of survivors with good outcome varies around $75 \%{ }^{30}$. The rate of death is low, but this might be underestimated because patients admitted in a critical neurological state due to a malignant infarct, a potential effect of SCAD, do not always undergo complete diagnostic investigation.

Arterial outcome depends on the progress of the healing process and on the risk of dissection recurrence. Improvement of arterial lesions of dissection over time is frequent and strengthens the diagnosis ${ }^{46}$. Stenotic lesions resolve in about $70 \%$ of patients, but recanalization of oc- cluded vessels is less frequently observed, especially beyond three months ${ }^{30}$. Nevertheless, recanalization does not influence neurological outcome ${ }^{60}$. Aneurysms of the ICA frequently persist, whereas VA aneurysms tend to heal more often ${ }^{56,57}$. However, in ICA dissection, persistence of an aneurysm does not increase the risk for ischemia, new local symptoms, or arterial rupture ${ }^{51,57}$.

Recurrent dissection is rare and usually does not affect arteries previously involved ${ }^{2,14}$. The highest rate of recurrence $(2 \%)$ occurs within the first month after the initial event. After then, the risk is only about $1 \%$ per year ${ }^{14}$. However, patients with underlying vascular pathology, connective tissue disorders, fibromuscular dysplasia or a familial history of arterial dissection are under greater risk ${ }^{61}$.

Recurrent ischemic events after SCAD can result from recurrent dissection, persistent arterial lesion (occlusion or stenosis; rarely aneurysm) or other common causes of stroke in young subjects, and seem to be more frequent during the first weeks ${ }^{30,62}$. The annual risk of recurrent stroke after SCAD is, at most, 3.4\% per year po, $57,59,62^{\text {. }}$

In conclusion, SCAD is the cause of up to one-fourth of strokes in young and middle-aged patients. Growing awareness of its clinical features and advances in imaging technologies such as MRI, MRA and CTA, have improved diagnosis. Treatment based on antithrombotic drugs is empiric rather than evidence-based. Therefore, randomized controlled trials comparing anticoagulants with antiplatelets are needed. So far, studies devoted to the long-term risk of recurrent events have been rare and many uncertainties persist regarding the influence of antithrombotic drugs on the risk of ischemic events. Functional outcome depends on the severity of the ischemic insult. The arterial outcome is often good, and the healing process with recanalization does not directly influence functional prognosis.

\section{REFERENCES}

1. Caplan LR. Dissection of brain-supplying arteries. Nat Cli Pract Neurol 2008;4:34-42.

2. Schievink W. Spontaneous dissection of the carotid and vertebral arteries. N Eng J Med 2001;344:898-906.

3. Lucas C, Moulin T, Deplanque D, Tatu L, Chavot D. Stroke patterns of internal carotid artery dissection in 40 patients. Stroke 1998;29:2646-2648.

4. Mokri B, Sundt T, Houser O, Piepgras D. Spontaneous dissection of the cervical internal carotid artery. Ann Neurol 1986;19:126-138.

5. Caplan LR, Hennerici MG. Impaired clearance of emboli (washout) is an important link between hypoperfusion, embolism and ischemic stroke. Arch Neurol 1998;55:1475-1482.

6. Caplan LR, Wong KS, Gao S, Hennerici MG. Is hypoperfusion an important cause of strokes? If so, how? Cerebrovasc Dis 2006;21:145-153.

7. Anderson R, Schechter MM. A case of spontaneous dissecting aneurysm of internal carotid artery. J Neurol Neurosurg Psychiatry 1959;22:195-201.

8. De Bray JM, Baumgartner RW. History of spontaneous dissection of the cervical carotid artery. Arch Neurol 2005;62:1168-1170.

9. Fisher CM, Ojemann RG, Roberson GH. Spontaneous dissection of cervicocervical arteries. Can J Neurol Sci 1978;5:9-19.

10. Bogousslavsky J, Pierre P. Ischaemic stroke in patients under age 45 . Neurol Clin 1992;10:113-124

11. Lee VH, Brown RD Jr, Mandrekar JN, Mokri B. Incidence and out- 
come of cervical artery dissection: a population-based study. Neurology 2006;67:1809-1812.

12. Schievink WI, Mokri B, Whisnant JP. Internal carotid artery dissection in a community: Rochester, Minnesota, 1987-1992. Stroke 1993;24:1678-1680.

13. Schievink WI, Roiter V. Epidemiology of cervical artery dissection. In Bawngartner RW, Bogousslavsky J, Caso V, Paciaroni M (eds). Handbook on cerebral artery dissection. Front Neurol Neurosci: Basel, Karger, 2005;20:12-15.

14. Schievink WI, Mokri B, O'Fallon WM. Recurrent spontaneous cervical artery dissection. N Engl J Med 1994;330:393-397.

15. Brandt T, Orberk E, Weber R, et al. Pathogenesis of cervical artery dissections: association with connective tissue abnormalities. Neurology 2001;57:24-30.

16. Campos CR, Evaristo EF, Yamamoto FI, Puglia Jr P, Lucato LT, Scaff M. Dissecção espontânea cervical carotídea e vertebral: estudo de 48 pacientes. Arq Neuropsiquiatr 2004;62:492-498.

17. Pieri A, Spitz M, Valiente RA, Avelar WM, Silva GS, Massaro AR. Dissecção espontânea das artérias carótidas e vertebrais em uma população multiétnica. Arq Neuropsiquiatr 2007;65:1050-1055.

18. Pelkonen O, Tikkakoski T, Leinonen S, Pyhtinen J, Lepojarvi M, Sotanie$\mathrm{mi}$ K. Extracranial internal carotid and vertebral artery dissections: angiographic spectrum, course and prognosis. Neuroradiology 2003;45:71-77.

19. Sheth TN, Winslow JL, Mikulis DJ. Rotational changes in the morphology of the vertebral artery at a common site of artery dissection. Can Assoc Radiol J 2001;52:236-241.

20. Caso V, Paciaroni M, Bogousslavsky J. Enviromental factors and cervical artery dissection. In: Bawngartner RW, Bogousslavsky J, Caso V, Paciaroni M (eds): Handbook on Cerebral Artery Dissection. Front Neurol Neurosci. Basel: Karger, 2005;20:44-53.

21. Rothwell Dm, Bondy SJ, Williams JL. Chiropractic manipulation and stroke: a population-based case-control study. Stroke 2001;32:1054-1060.

22. Cassidy JD, Boyle E, Côté $\mathrm{P}$, et al. Risk of vertebrobasilar stroke and chiropractic care: results of a population-based case-control and casecrossover study. Spine 2008;15(Suppl):S176-S183.

23. Gallai V, Caso V, Paciaroni M, et al. Mild hyperhomocyst(e)inemia: a possible risk factor for cervical artery dissection. Stroke 2001;32:714-718.

24. Grond-Ginsbach C, Debette S, Pezzini A. Genetic approaches in the study of risk factors for cervical artery dissection. In: Bawngartner RW, Bogousslavsky J, Caso V, Paciaroni M (eds): Handbook on cerebral artery dissection. Front Neurol Neurosci. Basel: Karger 2005;20:30-43.

25. D'Anglejan-Chantillon J, Ribeiro V, Mas JL, Youl BD, Bousser MG. Migraine: a risk factor for dissection of cervical arteries. Headache 1989;29:560-561.

26. Pezzini A, Granella F, Grassi M, et al. History of migraine and the risk of spontaneous cervical artery dissection. Cephalalgia 2005;25:575-580.

27. Guillon B, Berthet K, Benslamia L, Bertrand M, Bousser MG, Tzourio C. Infection and the risk of spontaneous cervical artery dissection: a casecontrol study. Stroke 2003;34:e79-e81.

28. Schievink WI, Michels VV, Piepgras DG. Neurovascular manifestations of heritable connective tissue disorders (review). Stroke 1994;25:889-903.

29. Brandt T, Hausser I, Orberk E, et al. Ultrastructural connective tissue abnormalities in patients with spontaneous cervicocerebral artery dissections. Ann Neurol 1998;44:281-285.

30. Touzé E, Gauvrit JY, Meder JF, Mas JL. Prognosis in cervical artery dissection. In: Bawngartner RW, Bogousslavsky J, Caso V, Paciaroni M (eds): Handbook on cerebral artery dissection. Front Neurol Neurosci Basel: Karger 2005;20:129-139.

31. Biousse V, D'Anglejan-Chatillon J, Touboul PJ, Amarenco P, Bousser MG. Time course of symptoms in extracranial carotid artery dissections. A series of 80 patients. Stroke 1995;26:235-239.

32. Silbert PL, Mokri B, Schievink WI. Headache and neck pain in spontaneous internal carotid and vertebral artery dissections. Neurology 1995;45:1517-1522.

33. Campos CR, Calderaro M, Scaff M, Conforto AB. Primary headaches and painful spontaneous cervical artery dissection.J Headache Pain 2007;8:180-184.

34. Baumgartner RW, Arnold M, Baumgartner I, et al. Carotid dissection with and without ischemic events: local symptoms and cerebral artery findings. Neurology 2001;57:827-832.

35. Baumgartner RW, Bogousslavsky J. Clinical manifestations of carotid dissection. In: Bawngartner RW, Bogousslavsky J, Caso V, Paciaroni M (eds): Handbook on cerebral artery dissection. Front Neurol Neurosci Basel, Karger 2005;20:70-76.

36. De Bray JM, Baumgartner RW, Guillon B, et al. Isolated Horner's syndrome may herald stroke. Cerebrovasc Dis 2005;19:274-275.

37. Arnold M, Bousser MG. Clinical manifestations of vertebral artery dissection. In Bawngartner RW, Bogousslavsky J, Caso V, Paciaroni M (eds): Handbook on cerebral artery dissection. Front Neurol Neurosci Basel: Karger 2005;20:77-86.

38. Mokri B, Houser OW, Sandok BA, Piepgras DG. Spontaneous dissection of the vertebral arteries. Neurology 1988;38:880-885.

39. Biousse V, Schaison M, Touboul PJ, D'Anglejan-Chatillon J, Bousser MG. Ischemic optic neuropathy associated with internal carotid artery dissection. Arch Neurol 1998;55:715-719.

40. Arnold M, Bousser MG, Fahrni G, et al. Vertebral artery dissection: presenting findings and predictors of outcome. Stroke 2006;37:2499-2503.

41. Paciaroni M, Caso V, Agnelli G. Magnetic resonance imaging, magnetic resonance and catheter angiography for diagnosis of cervical artery dissection. In Bawngartner RW, Bogousslavsky J, Caso V, Paciaroni M (eds): Handbook on cerebral artery dissection. Front Neurol Neurosci Basel: Karger 2005;20:102-118.

42. Provenzale JW. Dissection of the internal carotid and vertebral arteries: Imaging features. AJR Am J Roentgenol 1995;165:1099-1104.

43. Taschner CA, Leclerc X, Lucas C, Pruvo JP. Computed tomography angiography for the evaluation of carotid artery dissections. In Bawngartner RW, Bogousslavsky J, Caso V, Paciaroni M (eds): Handbook on cerebral artery dissection. Front Neurol Neurosci. Basel: Karger 2005;20:119-128.

44. Benninger DH, Caso V, Baumgartner RW. Ultrasound assessment of cervical artery dissection. In Bawngartner RW, Bogousslavsky J, Caso V, Paciaroni M (eds): Handbook on cerebral artery dissection. Front Neurol Neurosci. Basel: Karger 2005;20:87-101.

45. Beletsky V, Nadareishvili Z, Lynch J, Shuaib A, Woolfenden A, Norris JW. Cervical arterial dissection: time for a therapeutic trial? Stroke 2003;34:2856-2860.

46. Hart RG, Easton JD. Dissections of cervical and cerebral arteries. Neurol Clin 1983;1:155-582.

47. Georgiadis D, Baumgartner RW. Thrombolysis in cervical artery dissection. In Bawngartner RW, Bogousslavsky J, Caso V, Paciaroni M (eds): Handbook on cerebral artery dissection. Front Neurol Neurosci. Basel: Karger: 2005;20:140-146.

48. Rudolf J, Neveling M, Grond M, Schmulling S, Stenzel C, Heiss W. Stroke following internal carotid artery occlusion: a contra-indication for intravenous thrombolysis? Eur J Neurol 1999;6:51-55.

49. Derex L, Nighoghossian N, Turjman F, et al. Intravenous tPA in acute ischemic stroke related to internal carotid artery dissection. Neurology 2000;54:2159-2161.

50. Arnold M, Nedeltchev K, Sturzenegger M, et al. Thrombolysis in patients with acute stroke caused by cervical artery dissection: analysis of 9 patients and review of the literature. Arch Neurol 2002;59:549-553.

51. Georgiadis D, Schwab S, Engelter S, et al. Intravenous thrombolysis in patients with acute stroke due to spontaneous carotid dissection. Neurology 2005;64:1612-1614.

52. Baumgartner RW. Stroke prevention and treatment in patients with spontaneous carotid dissection. Acta Neurochir 2008(Suppl);103:S47-S50.

53. Zaidat OO, Fernandes Filho JA, Singh G, Suarez JI. Thrombolytic therapy for acute extracranial artery dissection: reporto of two cases. Arq Neuropsiquiatr 2001;59:936-938.

54. Cosottini M, Michelassi M, Puglioli M, et al. Silent cerebral ischemia detected with diffusion-weighted imaging in patients treated with protected and unprotected carotid artery stenting. Stroke 2005;36:2389-2393.

55. Kremer C, Mosso M, Georgiadis D, et al. Carotid dissection with permanent and transient occlusion or severe stenosis: long-term outcome. Neurology 2003;60:271-275.

56. Touzé E, Randoux B, Meary E, Arquizan C, Meder JF, Mas JL. Aneurysmal forms of cervical artery dissection: associated factors and outcome. Stroke 2001;27:1804-1807.

57. Guillon B, Brunereau L, Biosse V, Djouhri H, Levy C, Bousser MG. Long term follow-up of aneurysms developed during extracranial internal carotid artery dissection. Neurology 1999;53:117-122.

58. Leys D, Bandu L, Henon H, et al. Clinical outcome in 287 consecutive young adults (15 to 45 years) with ischemic stroke. Neurology 2002;59: 26-33.

59. Kappele LJ, Adams HP Jr, Heffner ML, Torner JC, Gomez F, Biller J. Prognosis of young adults with ischemic stroke: a long-term follow-up study assessing recurrent vascular events and functional outcome in the Iowa Registry of Stroke in Young Adults. Stroke 1994;25:1360-1365.

60. Caso V, Paciaroni M, Corea F, et al. Recanalization of cervical artery dissection: influencing factors and role in neurological outcome. Cerebrovasc Dis 2004;17:93-97.

61. Schievink WI, Mokri B, Piepgras DG, Kuiper JD. Recurrent spontaneous arterial dissections: risk in familial versus nonfamilial disease. Stroke 1996;27:622-624.

62. Touzé E, Gauvrit JY, Moulin T, Meder JF, Bracard S, Mas JL. Risk of stroke and recurrent dissection after a cervical artery dissection: a multicenter study. Neurology 2003;61:1347-1351. 